\title{
CALAGEM SUPERFICIAL E COBERTURA DE AVEIA PRETA ANTECEDENDO OS CULTIVOS DE MILHO E SOJA EM SISTEMA PLANTIO DIRETO(1)
}

\author{
Eduardo Fávero Caires ${ }^{(2)}$, Fernando José Garbuio ${ }^{(3)}$, Luís Reynaldo \\ Ferracciú Alleoni $^{(4)}$ \& Michel Alexandro Cambri ${ }^{(5)}$
}

\begin{abstract}
RESUMO
Os resíduos de plantas de cobertura podem mobilizar cátions no solo e beneficiar a ação da calagem superficial, por meio da liberação de ácidos orgânicos de baixo peso molecular da fração solúvel dos resíduos. Entretanto, faltam estudos no campo que comprovem tais efeitos em sistema plantio direto. Para avaliar as alterações químicas do solo e a resposta do milho e da soja com a aplicação de doses de calcário dolomítico na superfície $\left(0,0,2,5,5,0\right.$ e 7,5 t ha $\left.\mathrm{t}^{-1}\right)$, na ausência e na presença de cobertura de aveia preta, foi realizado um experimento em um Latossolo Vermelho distrófico textura argilo-arenosa, há cinco anos no sistema plantio direto, em Ponta Grossa (PR). As doses de calcário foram aplicadas nas parcelas em novembro de $2000 \mathrm{e}$, nas subparcelas, foram realizados dois cultivos, sem e com aveia preta em 2001 e 2002, antecedendo as culturas de milho e soja. A massa de aveia preta produzida não foi influenciada pela aplicação de calcário, tendo-se obtido aproximadamente $4 \mathrm{t} \mathrm{ha}^{-1}$ de matéria seca de aveia, em 2001 e 2002. A calagem também não alterou a capacidade de neutralização do hidrogênio $\left(482 \mathrm{mmol}_{\mathrm{c}} \mathrm{kg}^{-1}\right)$, a soma de cátions solúveis $\left(29,5 \mathrm{mmol}_{\mathrm{c}} \mathrm{L}^{-1}\right)$ e a condutividade elétrica $\left(1.230 \mu \mathrm{S} \mathrm{cm}^{-1}\right)$ do extrato de aveia. $\mathrm{O}$

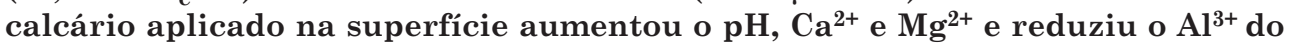
solo até à profundidade $\mathrm{de} 10 \mathrm{~cm}$. $\mathrm{O}$ resíduo de aveia preta mantido na superfície do solo não ocasionou benefícios à ação da calagem superficial na correção da acidez de camadas do subsolo. A calagem superficial não modificou a nutrição do milho, reduziu as concentrações de Zn e Mn nas folhas de soja e não causou
\end{abstract}

(1) Trabalho realizado com auxílio financeiro do CNPq. Recebido para publicação em dezembro de 2004 e aprovado em dezembro de 2005.

(2) Professor do Departamento de Ciência do Solo e Engenharia Agrícola, Universidade Estadual de Ponta Grossa - UEPG. Av. Gal. Carlos Cavalcanti 4748, CEP 84030-900 Ponta Grossa (PR). Bolsista do CNPq. E-mail: efcaires@uepg.br

(3) Mestrando em Agronomia, UEPG. Ex-bolsista do PIBIC/CNPq. E-mail: fgarbuio@yahoo.com.br

(4) Professor do Departamento de Solos e Nutrição de Plantas da Escola Superior de Agricultura Luiz de Queiroz - ESALQ/USP. Av. Pádua Dias 11, Caixa Postal 9, CEP 13418-900 Piracicaba (SP). Bolsista do CNPq. E-mail: lrfalleo@esalq.usp.br

(5) Doutor em Agronomia, Caixa Postal 39, CEP 68625-000 Paragominas (PA). E-mail: michel_cambri@yahoo.com.br 
alterações no rendimento de milho e soja. A cobertura de aveia preta aumentou as concentrações de $\mathrm{P}$, Ca e Mg, nas folhas de milho, de $\mathrm{N}$ e P, nas folhas de soja, e reduziu o Mn no tecido foliar de soja. A manutenção do resíduo de aveia preta sobre a superfície do solo aumentou o rendimento de milho, mas não influiu no rendimento de soja, cultivada após o milho, no sistema plantio direto.

Termos de indexação: acidez, subsolo, calcário dolomítico, resíduo vegetal, Glycine $\max ($ L.) Merrill, Zea mays L., nutrição mineral.

\title{
SUMMARY: SURFACE LIME APPLICATION AND BLACK OAT COVER PRECEDING CORN AND SOYBEAN CROPS UNDER A NO-TILL SYSTEM
}

\begin{abstract}
Cover crop residues mobilize cations and benefit the action of lime applied on the soil surface owing to the release of low molecular weight organic acids from the soluble fraction of residues. However, these effects in no-till system are yet to be confirmed in field studies. A five-year trial was carried out on a no-till dystrophic Rhodic Hapludox in Ponta Grossa, State of Paraná, Brazil, with the aim of evaluating changes in chemical soil attributes, as well as the corn and soybean response to surface application of dolomitic lime (0, 2.5, 5.0 and $\left.7.5 \mathrm{t} \mathrm{ha}^{-1}\right)$, with and without black oat cover. Lime rates were applied onto the main plots in November 2000 and the treatments on the subplots consisted of the presence or absence of black oat in 2001 and 2002, preceding corn and soybean crops. Surface-applied lime did not influence the dry matter yield of black oat, which was approximately $4 \mathrm{tha} \mathrm{h}^{-1} \mathrm{in}$ both 2001 and 2002 years. Liming did not affect the $\mathrm{H}^{+}$ions neutralizing capacity $\left(482 \mathrm{mmol}_{c} \mathrm{dm}^{-3}\right)$, the sum of soluble cations $\left(29.5 \mathrm{mmol}_{c} \mathrm{~L}^{-1}\right)$ or electric conductivity $\left(1,230 \mu \mathrm{S} \mathrm{cm}^{-1}\right)$ of the black oat extract either. Liming applied on the soil surface decreased exchangeable $\mathrm{Al}^{3+}$ and increased $\mathrm{pH}$, exchangeable $\mathrm{Ca}^{2+}$ and exchangeable $\mathrm{Mg}^{2+}$ down to a $10 \mathrm{~cm}$ depth. Black oat residue on the soil surface under no-till did not benefit the mobility of surface-applied lime to alleviate subsoil acidity. Surface application of lime did not affect corn mineral nutrition or corn and soybean yields, but decreased $\mathrm{Zn}$ and $\mathrm{Mn}$ concentrations in soybean leaves. Cover black oat residue raised the $P, C a$, and $M g$ concentrations in the corn and $N$ and $P$ in the soybean leaves and caused a decrease of $M n$ concentration in the soybean leaves. The black oat cover on the soil surface increased corn yield, but did not affect soybean yield, grown under no-till after corn.
\end{abstract}

Index terms: acidity, subsoil, dolomitic limestone, plant residue, Glycine max (L.) Merrill, Zea mays L., mineral nutrition.

\section{INTRODUÇÃO}

O sistema plantio direto tem-se destacado como uma das estratégias mais eficazes para melhorar a sustentabilidade da agricultura em regiões tropicais e subtropicais, contribuindo para minimizar perdas de solo e de nutrientes por erosão. Esse sistema de manejo do solo sem preparo tem apresentado rápido crescimento em área cultivada no Brasil, ocupando, atualmente, cerca de 20 milhões de hectares.

A correção da acidez do solo no sistema plantio direto é realizada mediante aplicação de calcário na superfície, sem incorporação. A baixa mobilidade dos produtos de dissolução do calcário aplicado na superfície limita sua eficiência na redução da acidez em camadas subsuperficiais de solos com cargas variáveis. A calagem na superfície cria uma frente de correção da acidez do solo em profundidade, proporcional à dose e ao tempo (Caires et al., 2000; Rheinheimer et al., 2000). São vários os trabalhos que mostram efeitos positivos da calagem superficial mais pronunciados nas camadas superficiais do solo (Caires et al., 1998, 1999; Pöttker \& Ben, 1998; Rheinheimer et al., 2000; Moreira et al., 2001; Petrere \& Anghinoni, 2001; Ciotta et al., 2004). A aplicação superficial de calcário não tem um efeito rápido na redução da acidez do subsolo, que depende da lixiviação de sais, orgânicos e, ou, inorgânicos, através do perfil do solo.

O aporte de elevada quantidade de resíduos vegetais ao solo é um dos principais requisitos para o sucesso do sistema plantio direto em condições tropicais e subtropicais. Os materiais vegetais mantidos na superfície do solo podem aumentar o $\mathrm{pH}$ e reduzir o teor de Al (Miyazawa et al., 1993). Os resíduos de plantas de cobertura podem mobilizar 
cátions no solo e beneficiar a ação da calagem superficial de forma mais efetiva do que aqueles obtidos após a colheita de grãos de culturas comerciais, por meio da liberação de ácidos orgânicos de baixo peso molecular da fração solúvel dos resíduos (Franchini et al., 1999a,b; Cassiolato et al., 2000; Franchini et al., 2001; Miyazawa et al., 2002; Franchini et al., 2003).

O efeito do calcário adicionado sobre a superfície do solo, em quantidade requerida para neutralizar $200 \%$ da acidez potencial $(\mathrm{H}+\mathrm{Al})$, limitou-se aos primeiros $10 \mathrm{~cm}$ superficiais na ausência de resíduos de aveia (Cassiolato et al., 2000). A calagem, na presença de extratos de aveia (equivalente a $10 \mathrm{t} \mathrm{ha}^{-1}$ de massa seca), aumentou o $\mathrm{pH}$ e o $\mathrm{Ca}^{2+}$ e diminuiu o $\mathrm{Al}^{3+}$ até $25 \mathrm{~cm}$ de profundidade. O estudo foi realizado em colunas de PVC com amostras de um Latossolo Vermelho ácido com teor baixo de Corgânico total e alto de areia $\left(\mathrm{pH}\right.$ em $\mathrm{CaCl}_{2}$ de 4,1; teores de $\mathrm{Al}^{3+}, \mathrm{Ca}^{2+}, \mathrm{Mg}^{2+} \mathrm{e} \mathrm{K}^{+}$de $11,1,3,70,1,70 \mathrm{e}$ $0,50 \mathrm{mmol}_{\mathrm{c}} \mathrm{dm}^{-3}$, respectivamente; teor de $\mathrm{H}+\mathrm{Al}$ de $62,0 \mathrm{mmol}_{\mathrm{c}} \mathrm{dm}^{-3}$; teor de C-orgânico total de 7,6 $\mathrm{g} \mathrm{kg}^{-1}$; teor de argila de $270 \mathrm{~g} \mathrm{~kg}^{-1}$; teor de silte de $20 \mathrm{~g} \mathrm{~kg}^{-1} \mathrm{e}$ teor de areia de $710 \mathrm{~g} \mathrm{~kg}^{-1}$ ). Em condições semelhantes para o mesmo solo, Franchini et al. (2001) verificaram que o calcário aplicado na superfície, em quantidade equivalente à neutralização de $100 \%$ da acidez potencial $(\mathrm{H}+\mathrm{Al})$

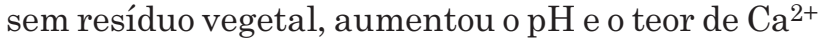
e diminuiu o teor de $\mathrm{Al}^{3+}$ apenas na camada de 0 $5 \mathrm{~cm}$ de profundidade. A calagem com resíduos de aveia preta e nabo forrageiro aumentou o $\mathrm{pH}$ e o teor de $\mathrm{Ca}^{2+}$ e diminuiu o teor de $\mathrm{Al}^{3+}$ na camada de 0-20 cm de profundidade.

Em outro estudo realizado em colunas de PVC com amostras de um Latossolo Vermelho ácido, mas com teores bem mais elevados de C-orgânico total e de argila ( $\mathrm{pH}$ em $\mathrm{CaCl}_{2}$ de 4,0; teores de $\mathrm{Al}^{3+}, \mathrm{Ca}^{2+}$, $\mathrm{Mg}^{2+} \mathrm{e} \mathrm{K}^{+}$de 19,0, 21,0, 10,0 e 4,0 $\mathrm{mmol}_{\mathrm{c}} \mathrm{dm}^{-3}$, respectivamente; teor de C-orgânico total de $30,9 \mathrm{~g} \mathrm{~kg}^{-1}$; teor de argila de $750 \mathrm{~g} \mathrm{~kg}^{-1}$; de silte de $100 \mathrm{~g} \mathrm{~kg}^{-1}$ e de areia de $150 \mathrm{~g} \mathrm{~kg}^{-1}$ ) também foi verificado que o efeito do calcário $\left(3 \mathrm{tha}^{-1}\right)$ sem resíduos vegetais limitou-se nos primeiros $10 \mathrm{~cm}$ de profundidade (Miyazawa et al., 2002). Os resíduos vegetais (equivalente a $40 \mathrm{t} \mathrm{ha}^{-1}$ de massa seca) junto com o calcário aceleraram os transportes de $\mathrm{Ca}^{2+} \mathrm{e}$ $\mathrm{Mg}^{2+}$ na seguinte ordem: aveia preta $>$ centeio $>$ mucuna $>$ leucena. As reduções nos teores de $\mathrm{Ca}^{2+}$ e $\mathrm{Mg}^{2+}$ do solo foram acompanhadas por aumentos no teor de $\mathrm{K}^{+}$. A formação de complexos organometálicos hidrossolúveis tem sido um mecanismo sugerido para as lixiviações de $\mathrm{Ca}^{2+} \mathrm{e}$ $\mathrm{Mg}^{2+}$ após a aplicação de calcário e resíduos vegetais no solo (Van der Watt et al., 1991; Noble et al., 1995).

A eficiência de extratos vegetais na neutralização da acidez da camada subsuperficial e no transporte de cátions polivalentes para o subsolo tem sido demonstrada por meio de estudos realizados em laboratório, com quantidades de resíduos muito superiores às introduzidas a cada ano no sistema plantio direto. Além disso, a reação da fração hidrossolúvel de resíduos vegetais no solo é extremamente rápida, sendo seus efeitos sobre a química da solução drasticamente reduzidos pelo processo de decomposição microbiana (Franchini et al., 1999a). Em um experimento realizado em colunas de PVC com amostras indeformadas de um Cambissolo argiloso manejado há cinco anos no sistema plantio direto, Amaral et al. (2004a) verificaram que os resíduos de aveia preta, ervilhaca e nabo forrageiro (equivalente a $10 \mathrm{t} \mathrm{ha}^{-1}$ de massa seca), na ausência ou na presença de calcário (13 t ha $\left.{ }^{-1}\right)$, não tiveram efeito na correção da acidez do solo em profundidade. O assunto é polêmico e, embora exista a possibilidade de serem os efeitos dos resíduos vegetais cumulativos ao longo dos anos no sistema plantio direto, precisa ser mais bem investigado mediante a realização de estudos no campo.

O presente trabalho objetivou avaliar as alterações químicas do solo e a resposta do milho e da soja após a aplicação de doses de calcário na superfície, na ausência e na presença de cobertura de aveia preta, em sistema plantio direto.

\section{MATERIAL E MÉTODOS}

O experimento foi realizado no município de Ponta Grossa (PR), $25^{\circ} 05^{\prime} 58$ " S e $50^{\circ} 09^{\prime} 30$ " W, em um Latossolo Vermelho distrófico textura argiloarenosa, manejado há cinco anos no sistema plantio direto. Análises químicas (Pavan et al., 1992) e granulométricas (Embrapa, 1997) do solo, na profundidade de $0-20 \mathrm{~cm}$, realizadas antes da instalação do experimento, revelaram os seguintes resultados: $\mathrm{pH}$ em $\mathrm{CaCl}_{2}$ 0,01 $\mathrm{mol} \mathrm{L}^{-1}$ 4,6; $77,3 \mathrm{mmol}_{\mathrm{c}} \mathrm{dm}^{-3}$ de $\mathrm{H}+\mathrm{Al} ; 2 \mathrm{mmol}_{\mathrm{c}} \mathrm{dm}^{-3}$ de $\mathrm{Al}^{3+}$;

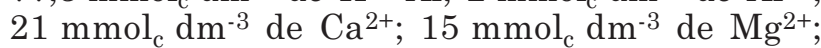
1,4 mmol $_{\mathrm{c}} \mathrm{dm}^{-3}$ de $\mathrm{K}^{+}$; 3,6 mg dm${ }^{-3}$ de P (Mehlich-1); $21 \mathrm{~g} \mathrm{dm}^{-3}$ de C-orgânico total e $33 \%$ de saturação por bases e teores de argila, silte e areia, respectivamente, de 440, 60 e $500 \mathrm{~g} \mathrm{~kg}^{-1}$.

$\mathrm{O}$ delineamento experimental empregado foi o de blocos completos ao acaso, em esquema de parcelas subdivididas, com três repetições. Em parcelas de 93,6 $\mathrm{m}^{2}$ (13,0 x 7,2 m), foram aplicadas na superfície, em novembro de 2000, quatro doses de calcário dolomítico $(26,5 \%$ de $\mathrm{CaO}, 20,2 \%$ de $\mathrm{MgO}$ e 82,0 \% de PRNT): 0,0, 2,5, 5,0 e 7,5 t ha ${ }^{-1}$. As doses de calcário foram calculadas, com vistas em elevar a saturação por bases da camada de $0-20 \mathrm{~cm}$ de solo a, aproximadamente, 50, 70 e $90 \%$. Em 2000-2001, a área experimental foi cultivada com soja. Em junho de 2001, as parcelas foram divididas em duas subparcelas de $46,8 \mathrm{~m}^{2}(6,5 \times 7,2 \mathrm{~m})$ : sem e com cobertura de aveia preta. Os tratamentos com 
aveia preta foram empregados nos anos de 2001 e 2002, antecedendo os cultivos de milho (2001-2002) e soja (2002-2003).

A aveia preta (Avena strigosa Schreb) foi semeada em junho de 2001 e em maio de 2002, na densidade de $80 \mathrm{~kg} \mathrm{ha}^{-1}$ de sementes e espaçamento de $0,17 \mathrm{~m}$ entre as linhas, sem adubação. No período de pleno florescimento da cultura, nos dois anos, coletou-se a parte aérea das plantas, em três linhas contínuas de $1,0 \mathrm{~m}\left(0,51 \mathrm{~m}^{2}\right)$, para avaliar a produção de matéria seca e a composição química do material vegetal. Logo após, realizou-se a dessecação da aveia com a aplicação de $2 \mathrm{~L} \mathrm{ha}^{-1}$ de glyphosate. $\mathrm{O}$ pH, a capacidade de neutralização do hidrogênio $(\mathrm{CNH})$, os teores de cátions solúveis e a condutividade elétrica do material vegetal foram determinados somente na aveia preta cultivada em 2001, conforme os métodos descritos em Miyazawa et al. (2000). Os teores de C-total (Tedesco et al., 1995) e de nutrientes (Malavolta et al., 1997) no resíduo de aveia foram determinados nos dois anos de cultivo.

O milho, híbrido SHS 5050, foi semeado em 12 de setembro de 2001, na densidade de cinco sementes por metro e espaçamento de $0,80 \mathrm{~m}$ entre as linhas. A adubação utilizada na semeadura foi de $330 \mathrm{~kg} \mathrm{ha}^{-1}$ da fórmula 10-20-20 e, em cobertura, foram aplicados $275 \mathrm{~kg} \mathrm{ha}^{-1}$ da fórmula 36-00-12, logo após a emissão da quarta folha.

A soja, cultivar CD 206, foi semeada em 10 de novembro de 2002 , na densidade de 20 sementes por metro e espaçamento de $0,45 \mathrm{~m}$ entre as linhas. A adubação utilizada na semeadura foi de $220 \mathrm{~kg} \mathrm{ha}^{-1}$ da fórmula 0-20-20. Realizou-se, também, a inoculação das sementes com estirpes selecionadas de Bradyrhizobium japonicum.

No início do florescimento das culturas de milho e soja, coletaram-se amostras de folhas em 30 plantas de cada subparcela. Na cultura do milho, retirou-se o terço médio da folha imediatamente abaixo e oposta à espiga. No caso da soja, foram coletadas as terceiras folhas a partir do ápice das plantas. As concentrações de $\mathrm{N}, \mathrm{P}, \mathrm{K}, \mathrm{Ca}, \mathrm{Mg}, \mathrm{S}$, $\mathrm{Cu}, \mathrm{Zn}$ e $\mathrm{Mn}$ nas folhas foram determinadas de acordo com os métodos descritos em Malavolta et al. (1997). Na maturação fisiológica do milho, foi retirada a parte aérea de cinco plantas inteiras ao acaso, por subparcela, para as determinações de produção de matéria seca e extração de $\mathrm{N}$ pelo milho.

Após a maturação, o milho e a soja foram colhidos e trilhados, determinando-se, então, o rendimento de grãos a $13 \%$ de umidade. A colheita de milho foi realizada nas cinco linhas centrais por $4 \mathrm{~m}$ de comprimento $\left(16,0 \mathrm{~m}^{2}\right)$, e a de soja nas seis linhas centrais por $5 \mathrm{~m}$ de comprimento $\left(13,5 \mathrm{~m}^{2}\right)$ de cada subparcela.

Amostras de solo foram coletadas logo após a colheita do milho e da soja, aos 18 e 30 meses da calagem na superfície. A amostragem de solo foi realizada por meio de trado, retirando-se 12 subamostras por subparcela para constituir uma amostra composta das camadas de 0-5, 5-10 e 10$20 \mathrm{~cm}$, e cinco subamostras para a camada de 20 $40 \mathrm{~cm}$ de profundidade. Determinaram-se o $\mathrm{pH}$ e os teores de $\mathrm{Al}^{3+}, \mathrm{Ca}^{2+}, \mathrm{Mg}^{2+}, \mathrm{K}^{+}$e C-orgânico total, segundo Pavan et al. (1992). Realizaram-se, também, análises de $\mathrm{S}-\mathrm{SO}_{4}{ }^{2-}$, nas diferentes profundidades do solo, mediante extração pelo acetato de amônio $0,5 \mathrm{~mol} \mathrm{~L}^{-1}$ em ácido acético $0,25 \mathrm{~mol} \mathrm{~L}^{-1}$ e posterior determinação pelo método turbidimétrico (Vitti \& Suzuki, 1978).

A precipitação pluvial ocorrida nos anos de 2000, 2001, 2002 e 2003 foi, respectivamente, de 1.734, $1.850,1.650$ e 1.549 mm. Não houve limitação hídrica durante o período de desenvolvimento das culturas no campo. A precipitação pluvial acumulada até os 18 e 30 meses depois da aplicação superficial do calcário foi de 2.826 e $4.364 \mathrm{~mm}$, respectivamente.

Os resultados foram submetidos às análises de variância e de regressão polinomial. Foram ajustadas equações de regressão aos dados obtidos de acordo com as doses de calcário, adotando-se, como critério para escolha do modelo, a magnitude dos coeficientes de determinação significativos a $5 \%$. Os efeitos da cobertura de aveia preta foram analisados pelo teste $\mathrm{F}$ e comparados pelo teste de Tukey a $5 \%$.

\section{RESULTADOS E DISCUSSÃO}

A massa de aveia preta produzida, nos dois anos estudados, não foi influenciada pelas doses de calcário aplicadas na superfície (Quadro 1). A produção média, em cada ano avaliado, foi da ordem de $4 \mathrm{t} \mathrm{ha}^{-1}$ de matéria seca de aveia preta. A calagem também não proporcionou alterações significativas no $\mathrm{pH}$, na capacidade de neutralização do hidrogênio $(\mathrm{CNH})$, nos teores de cátions solúveis $\left(\mathrm{Ca}^{2+}, \mathrm{Mg}^{2+}\right.$, $\mathrm{K}^{+}$e $\mathrm{Na}^{+}$) e na condutividade elétrica (CE) do extrato de aveia preta. As características da cobertura de aveia preta utilizada foram semelhantes às obtidas em outros trabalhos realizados em laboratório para CNH (Miyazawa et al., 1993), pH e soma de cátions (Franchini et al., 1999b, 2001; Meda et al., 2001).

As determinações de $\mathrm{CNH}$, soma de cátions solúveis e $\mathrm{CE}$ do extrato de plantas têm-se correlacionado com os efeitos dos materiais vegetais no aumento do $\mathrm{pH}$ e do Ca trocável e na diminuição do Al trocável no solo (Miyazawa et al., 1993; Franchini et al., 1999a; Meda et al., 2001; Cassiolato et al., 2002). Isso porque a capacidade de mobilização de cátions pelos materiais vegetais em solos ácidos está relacionada com o teor de ácidos orgânicos de 
Quadro 1. Produção de massa seca, pH, capacidade de neutralização do hidrogênio (CNH), teores de cátions solúveis e condutividade elétrica (CE) do extrato de aveia preta, considerando a calagem na superfície em sistema plantio direto

\begin{tabular}{|c|c|c|c|c|c|c|c|c|c|c|}
\hline \multirow{2}{*}{ Calcário } & \multicolumn{2}{|c|}{$\begin{array}{c}\text { Massa seca de } \\
\text { aveia }\end{array}$} & \multirow{2}{*}{$\mathrm{pH}^{(1)}$} & \multirow{2}{*}{ CNH(1) } & \multicolumn{4}{|c|}{ Cátion solúvel } & \multirow{2}{*}{$\begin{array}{l}\text { Soma de } \\
\text { cátions }\end{array}$} & \multirow{2}{*}{ CE (1) } \\
\hline & 2001 & 2002 & & & $\mathrm{Ca}^{2+}$ & $\mathbf{M g}^{2+}$ & $\mathbf{K}^{+}$ & $\mathrm{Na}^{+}$ & & \\
\hline $\mathrm{t} \mathrm{ha}^{-1}$ & \multicolumn{2}{|c|}{ — $\mathrm{kg} \mathrm{ha}^{-1} \_$} & & $\mathrm{mmol}_{\mathrm{c}} \mathrm{kg}^{-1}$ & 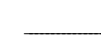 & 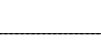 & $\mathrm{mmol}_{\mathrm{c}}$ & 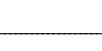 & - & $\mu \mathrm{S} \mathrm{cm}-1$ \\
\hline $\begin{array}{l}0,0 \\
2,5 \\
5,0 \\
7,5\end{array}$ & $\begin{array}{l}4.078 \\
3.874 \\
4.155 \\
4.220\end{array}$ & $\begin{array}{l}4.071 \\
4.394 \\
3.968 \\
3.807\end{array}$ & $\begin{array}{l}6,3 \\
6,5 \\
6,3 \\
6,5\end{array}$ & $\begin{array}{l}468,3 \\
486,9 \\
521,5 \\
450,3\end{array}$ & $\begin{array}{l}2,2 \\
2,1 \\
2,1 \\
2,2\end{array}$ & $\begin{array}{l}9,1 \\
9,5 \\
9,4 \\
9,4\end{array}$ & $\begin{array}{l}15,6 \\
15,3 \\
15,9 \\
15,1\end{array}$ & $\begin{array}{l}2,3 \\
2,5 \\
2,4 \\
2,9\end{array}$ & $\begin{array}{l}29,2 \\
29,4 \\
29,8 \\
29,6\end{array}$ & $\begin{array}{l}1.195 \\
1.273 \\
1.230 \\
1.223\end{array}$ \\
\hline Efeito & ns & ns & ns & ns & ns & ns & ns & ns & ns & ns \\
\hline C.V. (\%) & 10,8 & 21,2 & 3,1 & 14,8 & 10,0 & 8,8 & 8,3 & 17,8 & 5,7 & 6,9 \\
\hline
\end{tabular}

(1) Determinações realizadas na aveia preta em 2001. ns: efeito não-significativo por regressão polinomial.

baixo peso molecular da fração solúvel dos resíduos (Franchini et al., 2001, 2003). Na planta, esses compostos estão presentes na forma de ânions orgânicos para a manutenção de sua eletroneutralidade química, em decorrência da absorção de cátions básicos. A determinação de cátions no tecido vegetal, sendo relativamente mais fácil do que a de ânions orgânicos, tem sido apontada como um dos melhores indicadores dos efeitos dos resíduos na química da solução de solos ácidos (Franchini et al., 2004). $\mathrm{O}$ resíduo de aveia preta tem-se destacado como um material com grande capacidade para mobilizar $\mathrm{Ca}$ no solo porque apresenta alto teor de $\mathrm{K}$ no tecido (Franchini et al., 1999b; Ziglio et al., 1999; Cassiolato et al., 2000; Miyazawa et al., 2002).

A análise de variância dos resultados de análise química do solo, nas quatro profundidades estudadas, não revelou interação significativa entre os tratamentos com doses de calcário e cobertura de aveia preta. A ausência de interação indica que as modificações nos atributos químicos do solo, de acordo com as doses de calcário, não foram dependentes da cobertura vegetal.

As doses de calcário aplicadas na superfície aumentaram linearmente o $\mathrm{pH} \mathrm{em} \mathrm{CaCl}_{2}$ e os teores de $\mathrm{Ca}^{2+} \mathrm{e} \mathrm{Mg}^{2+}$ do solo até à profundidade de $10 \mathrm{~cm}$ (Quadro 2). Houve aumento significativo do $\mathrm{Ca}^{2+}$ apenas na camada mais superficial do solo $(0-5 \mathrm{~cm})$, após 18 meses, e na profundidade de $5-10 \mathrm{~cm}$, após 30 meses da aplicação do calcário. Os efeitos da calagem no aumento do $\mathrm{pH}$ e dos teores de $\mathrm{Mg}^{2+}$ foram significativos até à profundidade de $10 \mathrm{~cm}$ já aos 18 meses, permanecendo consistentes até 30 meses após a aplicação do calcário. A aplicação superficial de calcário não influenciou os teores de $\mathrm{K}^{+}$nas quatro profundidades estudadas. Os efeitos positivos da calagem na superfície em sistema plantio direto foram mais pronunciados nas camadas mais superficiais do solo, concordando com os resultados de outros trabalhos realizados na região Sul do Brasil (Caires et al., 1998, 1999; Pöttker \& Ben, 1998; Rheinheimer et al., 2000; Moreira et al., 2001; Petrere \& Anghinoni, 2001; Ciotta et al., 2004).

A cobertura de aveia preta não modificou o $\mathrm{pH}$

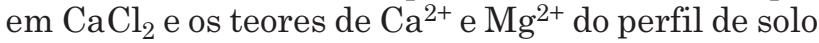
estudado $(0-40 \mathrm{~cm})$, durante os dois anos avaliados (Figura 1). Somente o teor de $\mathrm{K}^{+}$no solo foi significativamente aumentado na profundidade de 5-10 $\mathrm{cm}$ com a presença de cobertura de aveia preta, após a colheita do milho em 2002. Esses resultados, entretanto, são muito diferentes dos observados em outros estudos realizados em colunas de solo (Franchini et al., 1999b; Ziglio et al., 1999; Cassiolato et al., 2000; Franchini et al., 2001; Miyazawa et al., 2002) que mostraram importante efeito da aplicação de resíduo de aveia preta na neutralização da acidez

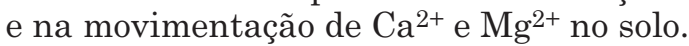

A provável explicação para essa discordância de resultados está relacionada com a quantidade muito superior de resíduos vegetais utilizada nos trabalhos feitos em colunas de solo (de até $40 \mathrm{t} \mathrm{ha}^{-1}$ ), em comparação com a massa seca de aveia preta produzida no presente trabalho ( $4 \mathrm{t} \mathrm{ha}^{-1}$ por ano) em condições de campo. Além disso, os efeitos de compostos orgânicos solúveis em plantas de cobertura sobre a química de solos ácidos são de curto prazo (Miyazawa et al., 1993) e se contrapõem aos efeitos de longo prazo associados com a dinâmica da matéria orgânica do solo (Franchini et al., 2004). Dessa forma, o cultivo de plantas leguminosas e o uso de fontes inorgânicas de $\mathrm{N}$ na rotação de culturas em plantio direto podem causar acidificação do solo com o tempo e anular o efeito de plantas de cobertura na neutralização da acidez. 
Quadro 2. Equações de regressão e coeficientes de determinação para atributos químicos do solo ( $\hat{y}$ ), em diferentes profundidades, considerando as doses de calcário na superfície (x, t ha $\left.{ }^{-1}\right)$, após 18 e 30 meses da aplicação

\begin{tabular}{|c|c|c|c|c|}
\hline$\hat{\mathrm{y}}$ & Profundidade & Tempo após a calagem & Equação de regressão & $\mathbf{R}^{2}$ \\
\hline \multirow[t]{8}{*}{$\mathrm{pH}$ em $\mathrm{CaCl}_{2}$} & $0-5$ & 18 & $\hat{y}=4,942+0,123 x$ & $0,92 * *$ \\
\hline & & 30 & $\hat{y}=4,943+0,187 x$ & $0,95^{* *}$ \\
\hline & $5-10$ & 18 & $\hat{y}=4,745+0,055 x$ & $0,50 *$ \\
\hline & & 30 & $\hat{y}=4,683+0,053 x$ & $0,93^{* *}$ \\
\hline & $10-20$ & 18 & $\hat{\mathrm{y}}=\overline{\mathrm{Y}}=4,9$ & - \\
\hline & & 30 & $\hat{\mathrm{y}}=\overline{\mathrm{Y}}=4,9$ & - \\
\hline & $20-40$ & 18 & $\hat{\mathrm{y}}=\overline{\mathrm{Y}}=4,8$ & - \\
\hline & & 30 & $\hat{\mathrm{y}}=\overline{\mathrm{Y}}=4,8$ & - \\
\hline \multirow[t]{8}{*}{ Ca trocável $\left(\mathrm{mmol}_{\mathrm{c}} \mathrm{dm}{ }^{-3}\right)$} & $0-5$ & 18 & $\hat{y}=34,467+2,187 x$ & $0,98^{* *}$ \\
\hline & & 30 & $\hat{y}=30,450+3,313 x$ & $0,89 * *$ \\
\hline & $5-10$ & 18 & $\hat{\mathrm{y}}=\overline{\mathrm{Y}}=28,5$ & - \\
\hline & & 30 & $\hat{y}=21,983+1,027 x$ & $0,98^{* *}$ \\
\hline & $10-20$ & 18 & $\hat{\mathrm{y}}=\overline{\mathrm{Y}}=26,8$ & - \\
\hline & & 30 & $\hat{\mathrm{y}}=\overline{\mathrm{Y}}=25,0$ & - \\
\hline & $20-40$ & 18 & $\hat{\mathrm{y}}=\overline{\mathrm{Y}}=21,5$ & - \\
\hline & & 30 & $\hat{\mathrm{y}}=\overline{\mathrm{Y}}=19,7$ & - \\
\hline \multirow[t]{8}{*}{ Mg trocável $\left(\mathrm{mmol}_{\mathrm{c}} \mathrm{dm}^{-3}\right)$} & $0-5$ & 18 & $\hat{y}=22,583+2,067 x$ & $0,99 * *$ \\
\hline & & 30 & $\hat{y}=17,450+2,480 x$ & $0,86^{* *}$ \\
\hline & $5-10$ & 18 & $\hat{y}=18,833+0,767 x$ & $0,87^{*}$ \\
\hline & & 30 & $\hat{y}=13,700+0,647 x$ & $0,80 *$ \\
\hline & $10-20$ & 18 & $\hat{\mathrm{y}}=\overline{\mathrm{Y}}=20,6$ & - \\
\hline & & 30 & $\hat{\mathrm{y}}=\overline{\mathrm{Y}}=15,3$ & - \\
\hline & $20-40$ & 18 & $\hat{\mathrm{y}}=\overline{\mathrm{Y}}=18,2$ & - \\
\hline & & 30 & $\hat{\mathrm{y}}=\overline{\mathrm{Y}}=15,2$ & - \\
\hline \multirow[t]{8}{*}{$\mathrm{K}$ trocável $\left(\mathrm{mmol}_{\mathrm{c}} \mathrm{dm}^{-3}\right)$} & $0-5$ & 18 & $\hat{\mathrm{y}}=\overline{\mathrm{Y}}=3,3$ & - \\
\hline & & 30 & $\hat{\mathrm{y}}=\overline{\mathrm{Y}}=3,5$ & - \\
\hline & $5-10$ & 18 & $\hat{\mathrm{y}}=\overline{\mathrm{Y}}=2,0$ & - \\
\hline & & 30 & $\hat{\mathrm{y}}=\overline{\mathrm{Y}}=1,9$ & - \\
\hline & $10-20$ & 18 & $\hat{\mathrm{y}}=\overline{\mathrm{Y}}=1,5$ & - \\
\hline & & 30 & $\hat{\mathrm{y}}=\overline{\mathrm{Y}}=1,7$ & - \\
\hline & $20-40$ & 18 & $\hat{\mathrm{y}}=\overline{\mathrm{Y}}=1,1$ & - \\
\hline & & 30 & $\hat{\mathrm{y}}=\overline{\mathrm{Y}}=1,5$ & - \\
\hline
\end{tabular}

*: $P<0,05 \mathrm{e}^{* *}: P<0,01$, por análise de regressão.

$\mathrm{O}$ aumento no $\mathrm{pH}$ do solo com a calagem resultou em redução nos teores de $\mathrm{Al}^{3+}$ (Figura 2). O solo apresentava baixos teores de $\mathrm{Al}^{3+}$, os quais foram menores que $5,0 \mathrm{mmol}_{\mathrm{c}} \mathrm{dm}^{-3}$ em todo o perfil estudado (0-40 cm), durante os 30 meses avaliados. Abreu Jr. et al. (2003) investigaram os componentes da acidez e suas relações com os atributos químicos de 26 solos de diferentes regiões brasileiras e mostraram que os teores de $\mathrm{Al}^{3+}$ diminuíram com o aumento do $\mathrm{pH}\left(\mathrm{CaCl}_{2} 0,01 \mathrm{~mol} \mathrm{~L}^{-1}\right)$ até 5,5 , concordando com os resultados obtidos no presente trabalho. 
$\mathrm{pH}\left(\mathrm{CaCl}_{2} \quad 0,01 \mathrm{~mol} \mathrm{~L}^{-1}\right)$
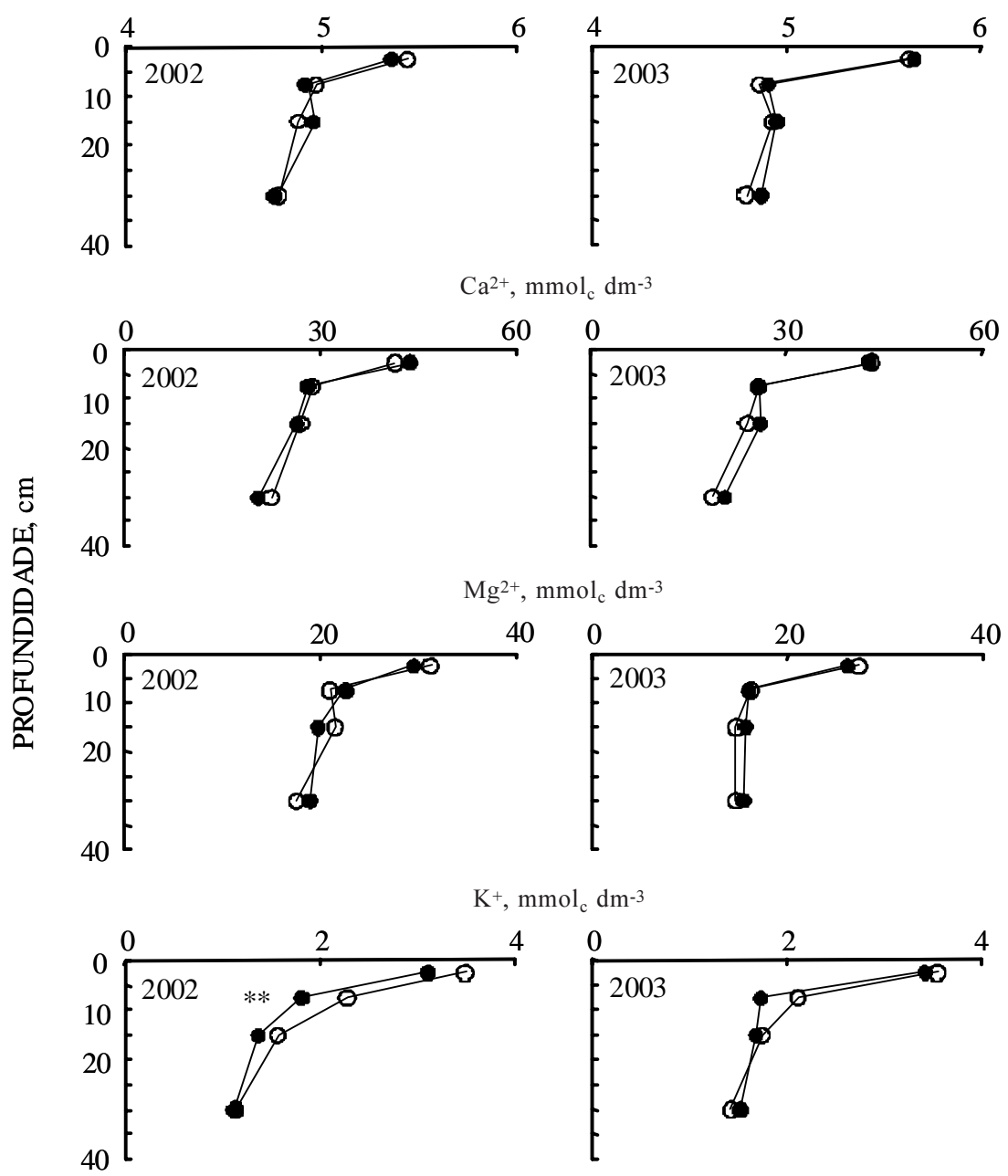

Figura 1. Valores de $\mathrm{pH}$ em $\mathrm{CaCl}_{2} 0,01 \mathrm{~mol} \mathrm{~L}^{-1}$ e teores de $\mathrm{Ca}^{2+}, \mathrm{Mg}^{2+}$ e $\mathrm{K}^{+}$, em diferentes profundidades do solo, na ausência $(O)$ e na presença $(\bigcirc)$ de cobertura de aveia preta, depois da colheita do milho em 2002 (18 meses após a calagem) e da soja em 2003 (30 meses após a calagem). **: $P<0,01$ pelo teste $\mathrm{F}$.

A aplicação superficial de calcário, independentemente da presença de cobertura de aveia preta (Figura 1), não foi efetiva na neutralização da acidez do solo em profundidades abaixo de $10 \mathrm{~cm}$ (Quadro 2). Assim, o resíduo de aveia preta mantido na superfície do solo em quantidades usualmente produzidas nas lavouras em plantio direto não ocasionou benefícios à ação da calagem superficial na correção da acidez de camadas do subsolo. Mesmo assim, existem trabalhos que mostraram consideráveis aumentos no $\mathrm{pH}$ em $\mathrm{CaCl}_{2}$ e nos teores de $\mathrm{Ca}^{2+} \mathrm{e} \mathrm{Mg}^{2+}$ em camadas subsuperficiais do solo com a aplicação de calcário na superfície em áreas manejadas em plantio direto (Oliveira \& Pavan, 1996; Caires et al., 2000). Nesses trabalhos, as variações nos atributos químicos da acidez em profundidade (20-40 e 40-60 cm), decorrentes da calagem na superfície, foram rápidas, variando de 8 a 12 meses após a aplicação do calcário. Embora o manejo de resíduos vegetais possa apresentar influência em tais efeitos (Oliveira \& Pavan, 1996), é preciso considerar as condições físicas do solo favoráveis ao deslocamento vertical de partículas finas de calcário (Amaral et al., 2004b) com o tempo de adoção do sistema plantio direto, tendo em vista que, no presente estudo, realizado em solo há apenas cinco anos em plantio direto, o efeito da calagem ficou restrito à camada de $0-10 \mathrm{~cm}$ e não foi influenciado pela cobertura vegetal.

A calagem e a cobertura de aveia preta não influíram nas concentrações de C-orgânico total e de $\mathrm{S}_{-} \mathrm{SO}_{4}{ }^{2-}$ disponíveis no solo (Figura 3). As quantidades de C-orgânico na aveia preta não foram alteradas pelas doses de calcário aplicadas na superfície, tendo-se adicionado ao solo, por meio da cobertura de aveia, 2.160 e $1.804 \mathrm{~kg} \mathrm{ha}^{-1} \mathrm{de}$ C-orgânico, em 2001 e 2002, respectivamente. Em estudo de longa duração, em sistema plantio direto, 
Ciotta et al. (2004) também mostraram que os teores de C-orgânico total e solúvel no solo não foram influenciados pela calagem. As maiores concentrações

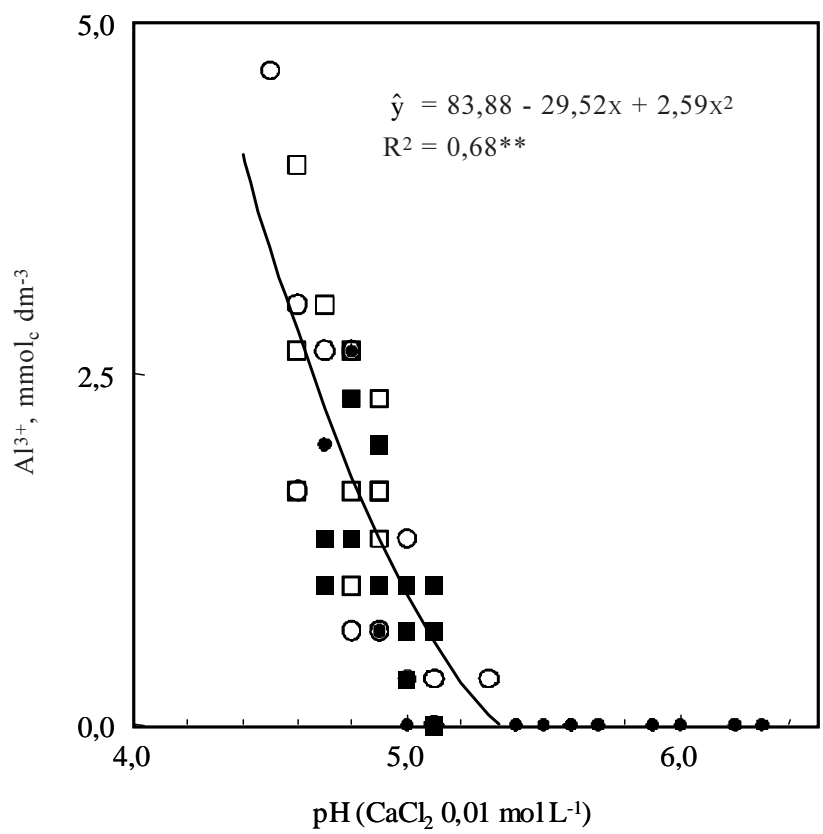

Figura 2. Relação entre o pH em $\mathrm{CaCl}_{2} 0,01 \mathrm{~mol} \mathrm{~L}^{-1}$ e o teor de $\mathrm{Al}^{3+}$, considerando a profundidade de 0-40 cm (O: 0-5 cm, $\bigcirc: 5-10 \mathrm{~cm}, \square: 10-20 \mathrm{~cm}$ e $\square: 20-40 \mathrm{~cm}) .{ }^{* *}: P<0,01$ pelo teste $\mathrm{F}$. de C-orgânico total ocorreram na camada superficial do solo $(0-5 \mathrm{~cm})$, superando em, aproximadamente, $25 \%$ o teor médio das demais profundidades. Mesmo assim, a amostragem de solo na profundidade de 0 $5 \mathrm{~cm}$ pode ter diluído um provável efeito da cobertura de aveia preta no aumento do teor de C-orgânico no solo. Isso porque a manutenção de resíduos orgânicos vegetais na superfície, em sistema plantio direto, aumenta a concentração de C-orgânico total, sobretudo nos primeiros 2,5 cm (Rhoton, 2000; Amaral et al., 2004a).

A adição de calcário pode melhorar o movimento de sulfato no solo (Camargo \& Raij, 1989), mas esse efeito não foi observado no presente estudo (Figura 3), concordando com os resultados de outros trabalhos realizados em sistema plantio direto (Caires et al., 1998, 2003, 2004). A cobertura de aveia preta não alterou a disponibilidade de $\mathrm{S}_{-} \mathrm{SO}_{4}{ }^{2-}$ certamente em razão das pequenas quantidades de $\mathrm{S}$ aportadas ao solo pelo resíduo de aveia (S, em kg ha ${ }^{-1}=6,2$ em 2001 e 4,8 em 2002). As concentrações médias de $\mathrm{S}_{-} \mathrm{SO}_{4}{ }^{2-}$ no solo foram de $11,0 \mathrm{mg} \mathrm{dm}^{-3}$, na camada de $0-20 \mathrm{~cm}$, e de $24,8 \mathrm{mg} \mathrm{dm}^{-3}$, na camada de $20-40 \mathrm{~cm}$. Cabe ressaltar que o sulfato é mais fortemente retido em solos mais ácidos e com menos carga elétrica negativa (Raij \& Peech, 1972). Isso e a repulsão do sulfato por fosfato explicam os teores mais baixos de $\mathrm{S}_{-} \mathrm{SO}_{4}{ }^{2-}$ na superfície do solo.

Não houve interação significativa entre os tratamentos com doses de calcário e cobertura de

(a)
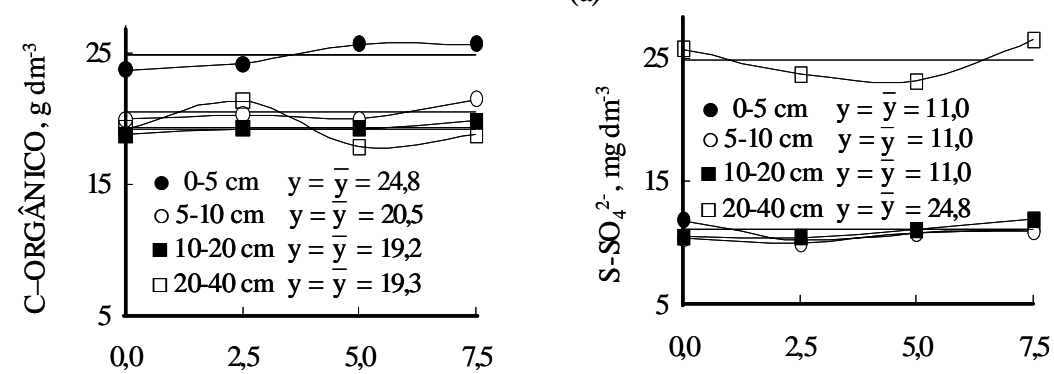

CALCÁRIO, $\mathrm{t}$ ha ${ }^{-1}$

(b)
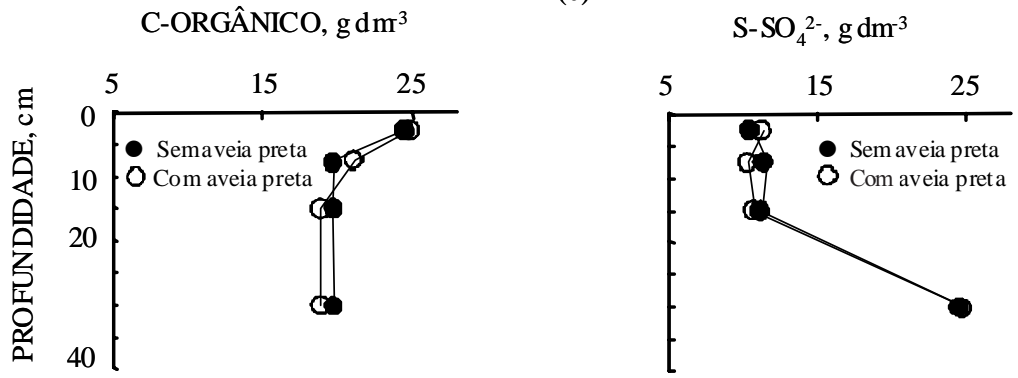

Figura 3. Teores de C-orgânico e de $\mathrm{S}_{-} \mathrm{SO}_{4}{ }^{2-}$ disponível, em diferentes profundidades do solo, considerando as doses de calcário após 30 meses da aplicação (a) e a cobertura de aveia preta depois da colheita da soja em 2003 (b). 
aveia preta para nenhuma das propriedades avaliadas nas plantas. Por essa razão, as respostas do milho e da soja, considerando as doses de calcário aplicadas e a cobertura de aveia preta, foram analisadas separadamente, por meio das médias dos tratamentos.

As concentrações de nutrientes nas folhas de milho (Quadro 3) e soja (Quadro 4) foram pouco influenciadas pela calagem e se mantiveram em níveis considerados normais para essas culturas (Malavolta et al., 1997). Na cultura do milho (Quadro 3), houve redução $(P<0,05)$ na concentração foliar de $\mathrm{N}\left(\hat{\mathrm{y}}, \mathrm{em} \mathrm{g} \mathrm{kg}^{-1}\right)$ de acordo com as doses de calcário aplicadas ( $\mathrm{x}$, em t ha ${ }^{-1}$ ), sendo a resposta linear $\left(\hat{y}=34,767-0,205 x, R^{2}=0,92\right)$. Possivelmente, esse efeito ocorreu por diluição do $\mathrm{N}$ nos tecidos da planta, porque a aplicação superficial de calcário não alterou a absorção de $\mathrm{N}$ pelo milho, avaliada na fase de maturação fisiológica da cultura, a qual foi, em média, de $208 \mathrm{~kg} \mathrm{ha}^{-1}$. Na soja (Quadro 4), as doses de calcário ( $\mathrm{x}$, em $\left.\mathrm{t} \mathrm{ha}^{-1}\right)$ reduziram linearmente $(P<0,05)$ os teores $(\hat{y}$, em $\left.m g \mathrm{~kg}^{-1}\right)$ de $\mathrm{Zn}\left(\hat{\mathrm{y}}=35,700-0,953 \mathrm{x}, \mathrm{R}^{2}=0,57\right)$ e $\mathrm{Mn}$ $\left(\hat{\mathrm{y}}=41,208-0,883 \mathrm{x}, \mathrm{R}^{2}=0,64\right)$ nas folhas. $\mathrm{O} \mathrm{pH}$ em $\mathrm{CaCl}_{2}$, na camada superficial do solo (Quadro 2), chegou a 5,9, depois da colheita do milho (18 meses após a calagem), e a 6,3, depois da colheita da soja (30 meses após a calagem), com a aplicação da maior dose de calcário $\left(7,5 \mathrm{t} \mathrm{ha}^{-1}\right)$. O decréscimo na absorção de Zn (Machado \& Pavan, 1987) e de Mn (Tanaka et al., 1992) pela soja é atribuído à diminuição da concentração da forma biodisponível na solução do solo com o aumento do $\mathrm{pH}$ pela calagem superficial (Caires et al., 2000).

As concentrações de $\mathrm{Ca}$ e $\mathrm{Mg}$ nas folhas de milho (Quadro 3) e soja (Quadro 4) não foram alteradas com a calagem, apesar de ter ocorrido aumento nos teores de $\mathrm{Ca}^{2+}$ e de $\mathrm{Mg}^{2+}$ nas camadas superficiais do solo por meio da aplicação de calcário dolomítico (Quadro 2). Os teores foliares de S nas culturas de milho (Quadro 3) e soja (Quadro 4), da mesma forma como ocorreu para os teores de $\mathrm{S}_{-} \mathrm{SO}_{4}{ }^{2-}$ disponível no solo (Figura 3), não foram influenciados pela aplicação de calcário. Concentrações de $\mathrm{S} \mathrm{SO}_{4}{ }^{2-}$ no solo $>10 \mathrm{mg} \mathrm{dm}^{-3}$ na profundidade de $0-20 \mathrm{~cm}$ (Figura 3) foram suficientes para garantir adequada nutrição de S para as culturas de milho (Quadro 3) e soja (Quadro 4).

O rendimento de grãos de milho (Quadro 3) e soja (Quadro 4) não foi influenciado pela calagem, tendose obtido rendimento médio de $9.240 \mathrm{~kg} \mathrm{ha}^{-1}$ de milho e $4.036 \mathrm{~kg} \mathrm{ha}^{-1}$ de soja. Altas produtividades de milho e soja, na ausência de calcário, também foram obtidas em outros estudos realizados em solos ácidos sob plantio direto no Sul do Brasil (Pöttker \& Ben, 1998; Caires et al., 1998, 1999, 2002, 2003; Moreira et al., 2001). Ressalta-se, no presente trabalho, que, apesar da acidez, o solo não apresentava teor tóxico de $\mathrm{Al}^{3+}$ (Figura 2) e tinha

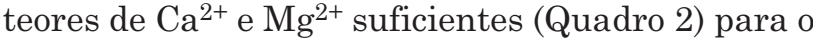
crescimento e desenvolvimento das culturas de milho e soja.

A cobertura de aveia preta proporcionou acréscimos significativos nas concentrações de $\mathrm{P}, \mathrm{Ca}$ e Mg nas folhas e no rendimento de grãos de milho (Quadro 3). A concentração foliar de N no milho não foi alterada pela cobertura vegetal. A aveia preta cultivada em 2001, antecedendo o milho, tinha relação $\mathrm{C} / \mathrm{N}$ de 31 pouco antes da dessecação (pleno florescimento), mas deve-se considerar que foram aplicados $132 \mathrm{~kg} \mathrm{ha}^{-1}$ de $\mathrm{N}$ na cultura do milho (33 $\mathrm{kg} \mathrm{ha}^{-1}$, na semeadura, e $99 \mathrm{~kg} \mathrm{ha}^{-1}$, em

Quadro 3. Concentração de nutrientes nas folhas e rendimento de milho, considerando as doses de calcário na superfície e a cobertura de aveia preta em sistema plantio direto

\begin{tabular}{|c|c|c|c|c|c|c|c|c|c|c|}
\hline Tratamento & $\mathbf{N}$ & $\mathbf{P}$ & $\mathbf{K}$ & $\mathrm{Ca}$ & Mg & $\mathbf{S}$ & $\mathbf{C u}$ & $\mathbf{Z n}$ & Mn & Rendimento de milho \\
\hline & 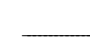 & & $-\mathrm{g}$ & & & - & 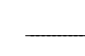 & $\mathrm{mg} \mathrm{ha}$ & - & $\mathrm{kg} \mathrm{ha-1}$ \\
\hline \multicolumn{11}{|l|}{ Calcário, t ha-1 } \\
\hline $\begin{array}{l}0,0 \\
2,5 \\
5,0 \\
7,5\end{array}$ & $\begin{array}{l}34,9 \\
34,2 \\
33,5 \\
33,4\end{array}$ & $\begin{array}{l}3,3 \\
3,2 \\
3,3 \\
3,4\end{array}$ & $\begin{array}{l}17,2 \\
19,2 \\
16,7 \\
16,7\end{array}$ & $\begin{array}{l}3,1 \\
4,0 \\
3,0 \\
3,8\end{array}$ & $\begin{array}{l}2,9 \\
4,0 \\
3,1 \\
3,6\end{array}$ & $\begin{array}{l}2,0 \\
2,1 \\
1,8 \\
1,8\end{array}$ & $\begin{array}{l}7,3 \\
8,0 \\
6,2 \\
9,5\end{array}$ & $\begin{array}{l}12,8 \\
11,0 \\
12,5 \\
12,5\end{array}$ & $\begin{array}{l}40,7 \\
34,5 \\
35,2 \\
32,2\end{array}$ & $\begin{array}{l}8.910 \\
9.288 \\
9.460 \\
9.300\end{array}$ \\
\hline Efeito & $\mathrm{L}^{*}$ & ns & ns & ns & ns & ns & ns & ns & ns & ns \\
\hline C.V. (\%) & 3,0 & 6,2 & 17,0 & 20,4 & 19,2 & 12,9 & 27,8 & 18,6 & 21,8 & 6,5 \\
\hline \multicolumn{11}{|l|}{ Cobertura vegetal } \\
\hline $\begin{array}{l}\text { Sem aveia preta } \\
\text { Com aveia preta } \\
\text { DMS }(P=0,05)\end{array}$ & $\begin{array}{r}33,4 \\
34,6 \\
1,4\end{array}$ & $\begin{array}{l}3,0 \\
3,6 \\
0,2\end{array}$ & $\begin{array}{r}17,1 \\
17,8 \\
2,3\end{array}$ & $\begin{array}{l}2,9 \\
4,1 \\
0,6\end{array}$ & $\begin{array}{l}3,0 \\
3,8 \\
0,4\end{array}$ & $\begin{array}{l}1,9 \\
1,9 \\
0,1\end{array}$ & $\begin{array}{l}7,8 \\
7,8 \\
1,2\end{array}$ & $\begin{array}{r}12,2 \\
12,3 \\
1,6\end{array}$ & $\begin{array}{r}34,4 \\
36,8 \\
5,0\end{array}$ & $\begin{array}{r}9.029 \\
9.450 \\
414\end{array}$ \\
\hline C.V. (\%) & 4,3 & 6,7 & 14,0 & 19,8 & 12,3 & 5,5 & 16,7 & 13,7 & 14,9 & 4,8 \\
\hline
\end{tabular}

L: efeito linear por regressão polinomial. ns: efeito não-significativo e *: $P<0,05$, por análise de regressão. 
Quadro 4. Concentração de nutrientes nas folhas e rendimento de soja, considerando as doses de calcário na superfície e a cobertura de aveia preta em sistema plantio direto

\begin{tabular}{|c|c|c|c|c|c|c|c|c|c|c|}
\hline Tratamento & $\mathbf{N}$ & $\mathbf{P}$ & $\mathbf{K}$ & $\mathrm{Ca}$ & Mg & $\mathbf{s}$ & $\mathrm{Cu}$ & Zn & Mn & Rendimento de soja \\
\hline & & & $-\mathrm{gk}$ & $g^{-1}$ & & - & 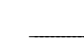 & $\mathrm{mg}$ ha & - & $\mathrm{kg} \mathrm{ha}^{-1}$ \\
\hline \multicolumn{11}{|l|}{ Calcário, t ha-1 } \\
\hline $\begin{array}{l}0,0 \\
2,5 \\
5,0 \\
7,5\end{array}$ & $\begin{array}{l}57,4 \\
59,0 \\
58,1 \\
59,4\end{array}$ & $\begin{array}{l}4,1 \\
4,2 \\
4,2 \\
4,3\end{array}$ & $\begin{array}{l}20,5 \\
20,7 \\
21,9 \\
22,5\end{array}$ & $\begin{array}{l}6,8 \\
6,6 \\
6,7 \\
6,5\end{array}$ & $\begin{array}{l}4,5 \\
4,5 \\
4,4 \\
4,6\end{array}$ & $\begin{array}{l}2,7 \\
2,8 \\
2,8 \\
2,8\end{array}$ & $\begin{array}{l}11,7 \\
11,7 \\
11,5 \\
12,0\end{array}$ & $\begin{array}{l}37,8 \\
31,5 \\
28,2 \\
31,0\end{array}$ & $\begin{array}{l}42,7 \\
36,0 \\
38,4 \\
34,5\end{array}$ & $\begin{array}{l}4.001 \\
3.871 \\
4.267 \\
4.006\end{array}$ \\
\hline Efeito & ns & ns & ns & ns & ns & ns & ns & $L^{*}$ & $L^{*}$ & ns \\
\hline C.V. (\%) & 5,3 & 10,1 & 13,4 & 8,4 & 5,3 & 15,9 & 23,9 & 14,2 & 12,2 & 10,3 \\
\hline \multicolumn{11}{|l|}{ Cobertura vegetal } \\
\hline $\begin{array}{l}\text { Sem aveia preta } \\
\text { Com aveia preta } \\
\text { DMS }(P=0,05)\end{array}$ & $\begin{array}{r}56,1 \\
60,9 \\
2,2\end{array}$ & $\begin{array}{l}3,8 \\
4,6 \\
0,4\end{array}$ & $\begin{array}{r}21,3 \\
21,5 \\
4,5\end{array}$ & $\begin{array}{l}6,8 \\
6,5 \\
0,4\end{array}$ & $\begin{array}{l}4,5 \\
4,5 \\
0,1\end{array}$ & $\begin{array}{l}2,8 \\
2,8 \\
0,4\end{array}$ & $\begin{array}{r}11,9 \\
11,5 \\
3,7\end{array}$ & $\begin{array}{r}31,2 \\
33,1 \\
4,4\end{array}$ & $\begin{array}{r}39,1 \\
36,7 \\
1,8\end{array}$ & $\begin{array}{r}3.999 \\
4.073 \\
249\end{array}$ \\
\hline C.V. (\%) & 4,1 & 10,2 & 22,6 & 6,8 & 3,3 & 15,8 & 33,9 & 14,5 & 5,0 & 6,5 \\
\hline
\end{tabular}

L: efeito linear por regressão polinomial. ns: efeito não-significativo $\mathrm{e}^{*}: P<0,05$, por análise de regressão.

cobertura). O S nas folhas de milho não foi influenciado pela cobertura de aveia preta porque os resíduos de aveia não proporcionaram alterações nos teores de $\mathrm{S}_{-} \mathrm{SO}_{4}{ }^{2-}$ disponível no solo (Figura 3). $\mathrm{O}$ aumento no teor de $\mathrm{K}^{+}$no solo, na profundidade de $5-10 \mathrm{~cm}$, ocasionado pela cobertura de aveia (Figura 1), não melhorou a nutrição de K do milho, certamente em razão dos teores suficientes desse nutriente no solo, decorrentes da adubação potássica realizada na cultura do milho. O aumento de $\mathrm{P}, \mathrm{Ca}$ e $\mathrm{Mg}$ no tecido foliar de milho na presença da cobertura vegetal pode ter sido ocasionado pela liberação desses nutrientes pela decomposição da palhada de aveia (Wisniewski \& Holtz, 1997), bem como pela manutenção de maior umidade disponível no solo (Salton \& Mielniczuk, 1995). De qualquer forma, o resíduo de aveia preta deixado sobre a superfície do solo no sistema plantio direto foi importante para melhorar a nutrição de $\mathrm{P}, \mathrm{Ca}$ e $\mathrm{Mg}$ e o rendimento de grãos de milho.

A cobertura de aveia preta aumentou $\mathrm{N}$ e $\mathrm{P}$ e reduziu Mn nas folhas de soja, sem causar reflexos no rendimento de grãos da cultura (Quadro 4). O aumento de $\mathrm{N}$ e $\mathrm{P}$ no tecido foliar da soja na presença da cobertura vegetal deve ter sido ocasionado pela mineralização da palhada de aveia (Wisniewski \& Holtz, 1997), embora a manutenção de maior umidade na camada superficial do solo, logo abaixo da cobertura formada pelos resíduos vegetais mantidos sobre a superfície, possa favorecer a difusão do $\mathrm{P}$ até às raízes (Phillips et al., 1980 citados por Muzilli, 1983). A relação $\mathrm{C} / \mathrm{N}$ da aveia preta no período de pleno florescimento foi um pouco mais baixa (26) em 2002, antes da soja, do que em 2001, antes do milho (31). Na região dos Campos Gerais do Paraná, em condições de solo e clima muito semelhantes às do presente trabalho, Wisniewski \& Holtz (1997) estimaram que $75 \%$ do N e $85 \%$ do $\mathrm{P}$ da palhada de aveia preta, mantida sobre a superfície do solo em sistema plantio direto, foram mineralizados em seis meses.

Deve-se considerar ainda que a soja foi cultivada depois da sucessão aveia preta-milho-aveia preta. A ausência de efeito da cobertura de aveia preta no rendimento de grãos de soja pode ter ocorrido em razão da elevada quantidade de massa seca de palha de milho, de aproximadamente $10,2 \mathrm{t} \mathrm{ha}^{-1}$, que foi deixada sobre a superfície do solo, depois de sua colheita. A redução da concentração foliar de $\mathrm{Mn}$ na soja proporcionada pela cobertura de aveia preta, está, provavelmente, relacionada com a diminuição do teor de Mn solúvel que ocorre em solo coberto com resíduos vegetais (Andrade et al., 1999 citados por Miyazawa et al., 2000).

\section{CONCLUSÕES}

1. A calagem na superfície, em sistema plantio direto, não foi efetiva na neutralização da acidez do solo em profundidades abaixo de $10 \mathrm{~cm}$. O resíduo de aveia preta mantido na superfície do solo em quantidades usualmente produzidas nas lavouras em plantio direto não ocasionou benefícios à ação da calagem superficial na correção da acidez de camadas do subsolo.

2. A aplicação superficial de calcário em solo ácido com baixos teores de $\mathrm{Al}^{3+}$ e com disponibilidade

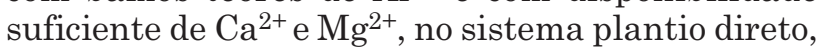
não modificou a nutrição do milho, reduziu as 
concentrações de Zn e Mn nas folhas de soja e não causou alterações no rendimento de grãos de milho e soja.

3. A cobertura de aveia preta aumentou as concentrações de $\mathrm{P}$, Ca e $\mathrm{Mg}$ nas folhas de milho, de $\mathrm{N}$ e $\mathrm{P}$ nas folhas de soja, bem como reduziu o $\mathrm{Mn}$ no tecido foliar da soja. A manutenção do resíduo de aveia preta sobre a superfície do solo no sistema plantio direto ocasionou acréscimo da ordem de $5 \%$ no rendimento de milho e não alterou o rendimento de soja cultivada após o milho.

\section{LITERATURA CITADA}

ABREU Jr., C.H.; MURAOKA, T. \& LAVORANTE, A.F. Relationship between acidity and chemical properties of Brazilian soils. Sci. Agric., 60:337-343, 2003.

AMARAL, A.S.; ANGHINONI, I. \& DESCHAMPS, F.C. Resíduos de plantas de cobertura e mobilidade dos produtos da dissolução do calcário aplicado na superfície do solo. R. Bras. Ci. Solo, 28:115-123, 2004a.

AMARAL, A.S.; ANGHINONI, I.; HINRICHS, R. \& BERTOL, I. Movimentação de partículas de calcário no perfil de um Cambissolo em plantio direto. R. Bras. Ci. Solo, 28:359-367, $2004 b$

CAIRES, E.F.; BANZATTO, D.A. \& FONSECA, A.F. Calagem na superfície em sistema plantio direto. R. Bras. Ci. Solo, 24:161-169, 2000.

CAIRES, E.F.; BARTH, G.; GARBUIO, F.J. \& KUSMAN, M.T. Correção da acidez do solo, crescimento radicular e nutrição do milho de acordo com a calagem na superfície em sistema plantio direto. R. Bras. Ci. Solo, 26:1011-1022, 2002.

CAIRES, E.F.; BLUM, J.; BARTH, G.; GARBUIO, F.J. \& KUSMAN, M.T. Alterações químicas do solo e resposta da soja ao calcário e gesso aplicados na implantação do sistema plantio direto. R. Bras. Ci. Solo, 27:275-286, 2003.

CAIRES, E.F.; CHUEIRI, W.A.; MADRUGA, E.F. \& FIGUEIREDO, A. Alterações de características químicas do solo e resposta da soja ao calcário e gesso aplicados na superfície em sistema de cultivo sem preparo do solo. R. Bras. Ci. Solo, 22:27-34, 1998.

CAIRES, E.F.; FONSECA, A.F.; MENDES, J.; CHUEIRI, W.A. \& MADRUGA, E.F. Produção de milho, trigo e soja em função das alterações das características químicas do solo pela aplicação de calcário e gesso na superfície, em sistema de plantio direto. R. Bras. Ci. Solo, 23:315-327, 1999.

CAIRES, E.F.; KUSMAN, M.T.; BARTH, G.; GARBUIO, F.J. \& PADILHA, J.M. Alterações químicas do solo e resposta do milho à calagem e aplicação de gesso. R. Bras. Ci. Solo, 28:125-136, 2004.

CAMARGO, O.A. \& RAIJ, B. van. Movimento do gesso em amostras de Latossolos com diferentes propriedades eletroquímicas. R. Bras. Ci. Solo, 13:275-280, 1989.
CASSIOLATO, M.E.; MEDA, A.R.; PAVAN, M.A.; MIYAZAWA, M. \& OLIVEIRA, J.C. Evaluation of oat extracts on the efficiency of lime in soil. Braz. Arch. Biol. Technol., 43:533536,2000

CASSIOLATO, M.E.; MIYAZAWA, M.; MEDA, A.R. \& PAVAN, M.A. A laboratory method to estimate the efficiency of plant extract to neutralize soil acidity. Braz. Arch. Biol. Technol., 45:183-187, 2002.

CIOTTA, M.N.; BAYER, C.; ERNANI, P.R.; FONTOURA, S.M.V.; WOBETO, C. \& ALBUQUERQUE, J.A. Manejo da calagem e os componentes da acidez de Latossolo Bruno em plantio direto. R. Bras. Ci. Solo, 28:317-326, 2004.

EMPRESA BRASILEIRA DE PESQUISA AGROPECUÁRIA EMBRAPA. Centro Nacional de Pesquisa de Solos. Manual de métodos de análise de solo. 2.ed. Rio de Janeiro, 1997. $212 p$.

FRANCHINI, J.C.; HOFFMANN-CAMPO, C.B.; TORRES, E.; MIYAZAWA, M. \& PAVAN, M.A. Organic composition of green manures during growth and its effect on cation mobilization in an acid Oxisol. Comm. Soil Sci. Plant Anal., $34: 2045-2058,2003$

FRANCHINI, J.C.; MALAVOLTA, E.; MIYAZAWA, M. \& PAVAN, M.A. Alterações químicas em solos ácidos após a aplicação de resíduos vegetais. R. Bras. Ci. Solo, 23:533$542,1999 \mathrm{a}$

FRANCHINI, J.C.; MEDA, A.R.; CASSIOLATO, M.E.; MIYAZAWA, M. \& PAVAN, M.A. Potencial de extratos de resíduos vegetais na mobilização do calcário no solo por método biológico. Sci. Agric., 58:357-360, 2001.

FRANCHINI, J.C.; MIYAZAWA, M. \& PAVAN, M.A. Influência de resíduos vegetais na toxidez de $\mathrm{Al}$ e na mobilidade de íons no solo. In: REUNIÃO BRASILEIRA DE FERTILIDADE DO SOLO E NUTRIÇÃO DE PLANTAS, 26., Lages, 2004. Anais. Lages, Sociedade Brasileira de Ciência do Solo, 2004. 6p. CD-ROM

FRANCHINI, J.C.; MIYAZAWA, M.; PAVAN, M.A. \& MALAVOLTA, E. Dinâmica de íons em solo ácido lixiviado com extratos de resíduos de adubos verdes e soluções puras de ácidos orgânicos. Pesq. Agropec. Bras., 34:2267-2276, 1999b.

MACHADO, P.L.O.A. \& PAVAN, M.A. Adsorção de zinco por alguns solos do Paraná. R. Bras. Ci. Solo, 11:253-256, 1987.

MALAVOLTA, E.; VITTI, G.C. \& OLIVEIRA, S.A. Avaliação do estado nutricional das plantas: princípios e aplicações. 2.ed. Piracicaba, POTAFOS, 1997. 319p.

MEDA, A.R.; CASSIOLATO, M.E.; PAVAN, M.A. \& MIYAZAWA, M. Alleviating soil acidity through plant organic compounds. Braz. Arch. Biol. Technol., 44:185-189, 2001.

MIYAZAWA, M.; PAVAN, M.A. \& CALEGARI, A. Efeito de material vegetal na acidez do solo. R. Bras. Ci. Solo, 17:411416, 1993.

MIYAZAWA, M.; PAVAN, M.A. \& FRANCHINI, J.C. Evaluation of plant residues on the mobility of surface applied lime. Braz. Arch. Biol. Technol., 45:251-256, 2002. 
MIYAZAWA, M.; PAVAN, M.A. \& FRANCHINI, J.C. Resíduos vegetais: influência na química de solos ácidos. In: SIMPÓSIO SOBRE FERTILIDADE DO SOLO E NUTRIÇÃO DE PLANTAS NO SISTEMA PLANTIO DIRETO, Ponta Grossa, 2000. Anais. Ponta Grossa, Associação dos Engenheiros Agrônomos dos Campos Gerais, 2000. p.82-94.

MOREIRA, S.G.; KIEHL, J.C.; PROCHNOW, L.I. \& PAULETTI, V. Calagem em sistema de semeadura direta e efeitos sobre a acidez do solo, disponibilidade de nutrientes e produtividade de milho e soja. R. Bras. Ci. Solo, 25:71-81, 2001.

MUZILLI, O. Influência do sistema de plantio direto, comparado ao convencional, sobre a fertilidade da camada arável do solo. R. Bras. Ci. Solo, 7:95-102, 1983.

NOBLE, A.D.; RANDALL, P.J. \& JAMES, T.R. Evaluation of two coal-derived organic products in ameliorating surface and subsurface soil acidity. Eur. J. Soil Sci., 46:65-75, 1995.

OLIVEIRA, E.L. \& PAVAN, M.A. Control of soil acidity in notillage system for soybean production. Soil Till. Res., 38:4757, 1996.

PAVAN, M.A.; BLOCH, M.F.; ZEMPULSKI, H.C.; MIYAZAWA, M. \& ZOCOLER, D.C. Manual de análise química do solo e controle de qualidade. Londrina, Instituto Agronômico do Paraná, 1992. 38p. (Circular, 76)

PETRERE, C. \& ANGHINONI, I. Alteração de atributos químicos no perfil do solo pela calagem superficial em campo nativo. R. Bras. Ci. Solo, 25:885-895, 2001.

PÖTTKER, D. \& BEN, J.R. Calagem para uma rotação de culturas no sistema de plantio direto. R. Bras. Ci. Solo, 22:675-684, 1998.

RAIJ, B. van \& PEECH, M. Electrochemical properties of some Oxisols and Alfisols of the tropics. Soil Sci. Soc. Am. Proc., 36:587-593, 1972.
RHEINHEIMER, D.S.; SANTOS, E.J.S.; KAMINSKI, J.; BORTOLUZZI, E.C. \& GATIBONI, L.C. Alterações de atributos do solo pela calagem superficial e incorporada a partir de pastagem natural. R. Bras. Ci. Solo, 24:797-805, 2000 .

RHOTON, F.E. Influence of time on soil response to no-till practices. Soil Sci. Soc. Am. J., 64:700-709, 2000.

SALTON, J.C. \& MIELNICZUK, J. Relações entre sistemas de preparo, temperatura e umidade de um Podzólico VermelhoEscuro de Eldorado do Sul (RS). R. Bras. Ci. Solo, 19:313319, 1995.

TANAKA, R.T.; MASCARENHAS, H.A.A. \& BULISANI, E.A. Deficiência de manganês em soja induzida por excesso de calcário. Pesq. Agropec. Bras., 27:247-250, 1992.

TEDESCO, M.J.; GIANELLO, C.; BISSANI, C. \& BOHNEN, H. Análise de solo, plantas e outros materiais. 2.ed. Porto Alegre, Universidade Federal do Rio Grande do Sul, 1995. 174p. (Boletim Técnico, 5)

Van der WATT, H.V.H.; BARNARD, R.O.; CRONJE, I.J.; DEKKER, J.; CROFT, G.J.B. \& Van der WALT, MARIA M. Amelioration of subsoil acidity by application of a coalderived calcium fulvate to the soil surface. Nature, 350:146148, 1991.

VITTI, G.C. \& SUZUKI, J.A. A determinação do enxofre - sulfato pelo método turbidimétrico. Jaboticabal, Universidade Estadual de São Paulo, 1978. 13p.

WISNIEWSKI, C. \& HOLTZ, G.P. Decomposição da palhada e liberação de nitrogênio e fósforo numa rotação aveia-soja sob plantio direto. Pesq. Agropec. Bras., 32:1191-1197, 1997.

ZIGLIO, C.M.; MIYAZAWA, M. \& PAVAN, M.A. Formas orgânicas e inorgânicas de mobilização do cálcio no solo. Braz. Arch. Biol. Technol., 42:257-262, 1999. 